\title{
DEVELOPMENT OF COMBUSTION MODEL IN THE INDUSTRIAL CYCLONE-CALCINER FURNACE USING CFD-MODELING
}

\author{
Roman Havryliv $^{1, *}$, Volodymyr Maystruk ${ }^{1}$
}

DOI: dx.doi.org/10.23939/chcht11.01.071

\begin{abstract}
A three-dimensional computer model has been developed for the simulation of combustion process, temperature fields and concentration species in the work section of industrial cyclone-calciner furnace. The RANSapproach with different turbulence models for modeling was used. Simulation results obtained with the model are compared with industrial furnace data. The results obtained with the computer model have important effects on the predicted temperature distribution in the furnace as well as on other significant design parameters for future theoretical and industrial research.
\end{abstract}

Keywords: CFD-modeling, combustion model, turbulence models, cyclone-calciner furnace.

\section{Introduction}

Turbulent combustion is the basis of many different industrial processes. These processes are used in a wide range of material processing industries, of which lime production is the most important.

Currently, lime is produced by limestone calcining in furnaces of various designs: shaft furnaces, rotary kilns, fluidized bed furnaces, and cyclone furnaces. Temperature is a crucial mode for operation of these furnaces and all the technical and economic performance of their work. The performance of the furnace systems deployed for fuel combustion is strongly dependent on the applied set-up, such as: furnace geometry, configuration of burner, composition of fuel and gas-air flows too.

For a long time, the industrial furnaces design was performed on the basis of empirical equations and physical experiments. This approach is very expensive and inaccurate, needed a lot of time for experimental studies. In addition, technological calcining process is a complicated dynamic object characterized by a large number of functionally related variables.

\footnotetext{
${ }^{1}$ Lviv Polytechnic National University

12, S. Bandera St., 79013 Lviv, Ukraine

havrilivroman@gmail.com

(C) Havryliv R., Maystruk V., 2017
}

Under such circumstances, the analysis of its dynamic properties often becomes possible only by using numerical modeling methods. Among the modern methods of numerical modeling, the CFD-methods are prevalent.

Computational fluid dynamics (CFD) simulations provide a much better insight into industrial combustion systems than any other technologies of modeling or measurements. It is possible to get information on temperature distribution, species concentrations, velocity distribution, heat transfer and the mixture of fuel and oxidizing fluid. Thus it is possible to see and solve potential problems even before combustion systems are constructed or in operation. However, it is necessary that the proposed model adequately describes the combustion process in the furnace.

In this article the investigation results of cyclone furnace calciner are presented. The present work is a step towards modeling the cyclone furnace used by "Pustomyty lime plant" (Pustomyty, Ukraine). The main focus is on the development of combustion model which adequately describes the temperature field in the working area of the apparatus and can be used in future studies to optimize the existing installation and analysis.

\section{Experimental}

\subsection{Materials and Methods of CFD-M odeling}

The gas-solid flow in cyclone furnace used by "Pustomyty lime plant" in Ukraine has been analyzed in a previous work [1]. The results obtained from CFD simulations were used to optimize furnace work. Experimental validations at the plant later confirmed that the results from simulations were indeed very effective and helped to improve the aerodynamics of the apparatus. However, there are many important questions which remain to be answered. 
The main question concerns the impact of the new regime apparatus which is proposed in [1] on the temperature field and particles calcinations process. To answer this question, the combustion computer model that will make it possible to evaluate temperature field in the apparatus must be developed.

Currently hydrodynamics modeling of the vortex gas flows in the apparatus of different designs based on CFD-modeling are widely studied [2,3]. ANSYS Fluent version 15 was used in this study to perform the simulation of the combustion process in the industrial cyclone-calciner furnace.

Firstly, based on the drawings of the industrial furnace, geometric model of the internal flows of the apparatus was built. Then by means of the mesh generator a computational mesh was created for this model. The resulting mesh contains 157985 Nodes and 847224 Elements. All geometric transformations were done in a software module Design Modeller, and the mesh was created in ANSYS Meshing. Modelled cyclone-calciner furnace is shown in Fig. 1a, b. The calcinations processes take place in the work zone 1 of the furnace, consisting of a $0.8 \mathrm{~m}$ diameter cylinder with $4.4 \mathrm{~m}$ height and the combustion processes take place in a conical section 2 .

Air is introduced into the calciner in two places. The primary air flow enters the burner 3 through the pipe
4 and additional flows enter the conical part of the calciner-furnace via two pipes 5 tangentially. The additional flows are inlet in the conical part of the calciner through the blades 9 where air creates a swirling of the flow. This mode of the furnace was described in [1] and called an additional mode of the apparatus.

The fuel (methane) enters the burner through the inlet tube 6, which has a circular shape. Natural gas and air run into a burning chamber and are mixed up. In the burner, the burnt fuel and gases are derived through a conical section 2 and cylindrical section 1 . In this type of furnace, the GGB-MGP-200 burner is used.

The $\mathrm{CaCO}_{3}$ particles are introduced to the conical section of the work zone through the tube 7 in central part of the calciner-furnace. The products such as calcined $\mathrm{CaO}$ solids, $\mathrm{CO}_{2}$, and other gases go out through the outlet tube 8 with a diameter of $0.485 \mathrm{~m}$. The total furnace volume is $3.4 \mathrm{~m}^{3}$.

In this study the mode without burning of limestone particles has been tested. Air enters into the burner through the pipe 4 only and the fuel (methane) enters into the burner through the inlet tube 6 . This mode is used to preheat the furnace.

All the geometric data and the initial and boundary conditions were supplied by "Pustomyty lime plant" (Ukraine).

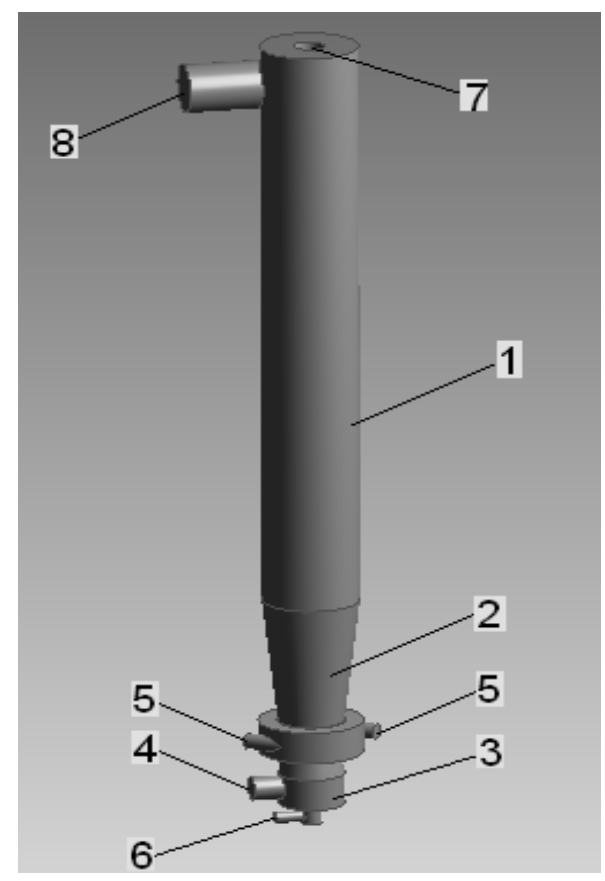

a)

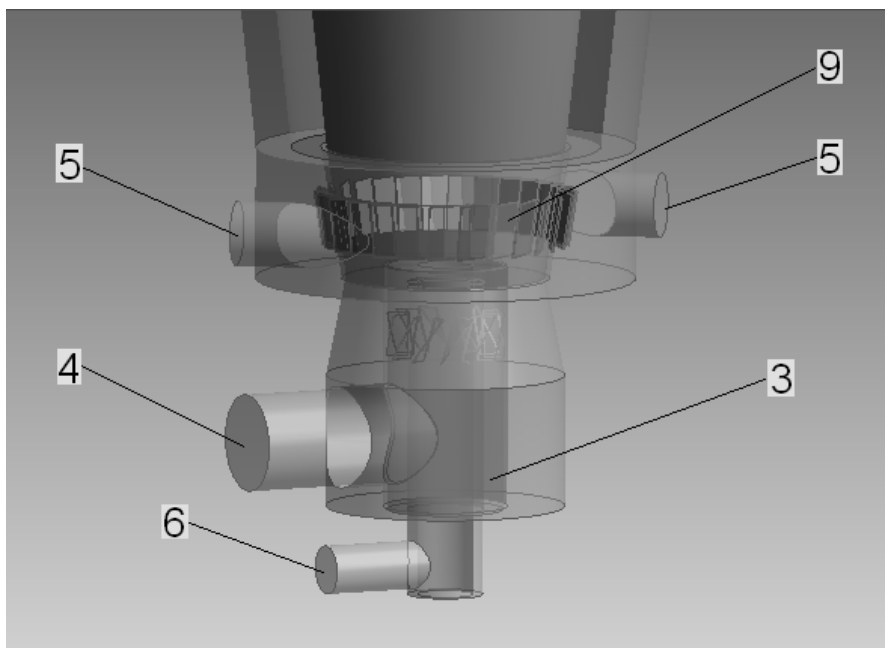

b)

Fig. 1. Cyclone-calciner furnace geometry: general view of furnace (a) and burner location (b) 


\subsection{Model Description and Boundary Conditions}

To simulate the diffusion methane-air combustion in a turbulent flow, two approaches in Ansys Fluent 15 were used. First, the most popular approach is eddydissipation model based on the work of Magnussen and Hjertager [4]. It is a turbulent-chemistry reaction model where the reaction rate will be determined assuming that turbulent mixing is the rate-limiting process with the turbulence-chemistry interaction modelled.

The combustion will be modelled using a global one-step reaction mechanism assuming complete conversion of the fuel (methane) to $\mathrm{CO}_{2}$ and $\mathrm{H}_{2} \mathrm{O}$. This reaction will be defined in terms of stoichiometric coefficients, formation enthalpies, and parameters that control the reaction rate. This mechanism gives the average value of enthalpy and is applicable to estimate the distribution of the main products of combustion $\left(\mathrm{CO}_{2}\right.$, $\mathrm{H}_{2} \mathrm{O}$ ) and temperature fields. Its advantage is simplicity and maximum simulation rate.

The second approach uses the Non-Premixed combustion model [5]. This model was used because the fuel as well as the oxidizer enters the burner of calciner furnace in different distinct streams. This software model simplifies the thermochemistry associated with this type of combustion through the use of the mixture fraction. This fraction is the mass fraction of the burnt and unburnt fuel elements in all of the species present.

This is an important technique because atomic elements are conserved during the reaction process, and the governing transport equation does not have a source term. Through the simplification of using the mixture fraction, closing non-linear mean reaction rates are no longer necessary since this is simply a mixing problem. The chemistry was modelled in the Chemical Equilibrium Model. This model allows including the effects of intermediate species as well as dissociation reactions, which creates a realistic approximation of the flame temperature.

Fluid flow will be modelled using the continuity (1), Navier-Stokes (2) and (3) energy equations shown below $[6,7]$ :

$$
\begin{gathered}
\frac{\partial \rho}{\partial t}+\operatorname{div}(\rho \stackrel{r}{\rho})=0 \\
\rho \frac{d u}{d t}=\rho \stackrel{r}{F}+\operatorname{div} \tau^{T} \\
\rho c_{p} \frac{d T}{d t}=E-\operatorname{div} \stackrel{r}{q}+q_{T}
\end{gathered}
$$

For an incompressible fluid flow $\rho=0$ and taking into account the internal friction Newton's law (1) and (2) equations are:

$$
\operatorname{div}(\dot{u})=0
$$

$$
\rho \frac{d u}{d t}=\stackrel{r}{F}-\frac{1}{\rho} \operatorname{gradp}+v \nabla^{2} \stackrel{r}{u}
$$

where $\rho$ - density; $u$-velocity; $\tau$ - stress tensor; $p$ - static pressure; $F$ - external body force; $c_{P}$ - heat capacity at constant pressure; $T$ - local temperature of flow; $E-$ energy dissipation; $q$ - specific local heat flux; $q_{T}-$ an additional source of heat (for example by chemical reaction); $v$ - kinematic viscosity of fluids.

There are the basic equations of hydrodynamics which represent the basic model of the medium flow [8]. Eq. (5) is the Navier-Stokes equation and for the Newtonian fluid in Cartesian coordinate system it can be written as:

$$
\begin{aligned}
& \frac{d u_{x}}{d t}=F_{x}-\frac{1}{\rho} \cdot \frac{\partial p}{\partial x}+v\left(\frac{\partial^{2} u_{x}}{\partial x^{2}}+\frac{\partial^{2} u_{x}}{\partial y^{2}}+\frac{\partial^{2} u_{x}}{\partial z^{2}}\right) \\
& \frac{d u_{y}}{d t}=F_{y}-\frac{1}{\rho} \cdot \frac{\partial p}{\partial y}+v\left(\frac{\partial^{2} u_{y}}{\partial x^{2}}+\frac{\partial^{2} u_{y}}{\partial y^{2}}+\frac{\partial^{2} u_{y}}{\partial z^{2}}\right) \\
& \frac{d u_{z}}{d t}=F_{z}-\frac{1}{\rho} \cdot \frac{\partial p}{\partial z}+v\left(\frac{\partial^{2} u_{z}}{\partial x^{2}}+\frac{\partial^{2} u_{z}}{\partial y^{2}}+\frac{\partial^{2} u_{z}}{\partial z^{2}}\right)
\end{aligned}
$$

where $v-$ kinematic viscosity. To approximate the continuity and Navier-Stokes equations for turbulent flow, the most popular method Reynolds-Averaged approach was used (RANS) [8-11]:

$$
\begin{gathered}
\frac{\partial \rho}{\partial t}+\frac{\partial}{\partial x_{i}}\left(\rho u_{i}\right)=0 \\
\frac{\partial}{\partial t}\left(\rho u_{i}\right)+\frac{\partial}{\partial x_{j}}\left(\rho u_{i} u_{j}\right)=-\frac{\partial p}{\partial x_{i}}+ \\
+\frac{\partial}{\partial x_{j}}\left[\mu\left(\frac{\partial u_{i}}{\partial x_{j}}+\frac{\partial u_{j}}{\partial x_{i}}-\frac{2}{3} \delta_{i j} \frac{\partial u_{l}}{\partial x_{l}}\right)\right]+\frac{\partial}{\partial x_{j}}\left(-\rho \bar{u}_{i}^{\prime} \bar{u}_{j}^{\prime}\right)
\end{gathered}
$$

where $\mu$-dynamic viscosity; $\vec{u}_{i}^{\prime}$ and $u_{i}^{\prime}$ are the mean and fluctuating velocity components and $\delta_{i j}$-delta function or the Kronecker delta.

Eqs. (7) and (8) are called Reynolds-averaged Navier-Stokes (RANS) equations. Additional terms $-\rho \bar{u}_{i}^{\prime} \bar{u}_{j}^{\prime}$ represent the effects of turbulence and are called the Reynolds stresses (also called turbulent stresses) and require additional modeling.

There are several approaches available in literature [12] for solution of the Reynolds stresses. Commonly used Boussinesq hypothesis [13] to relate the Reynolds stresses in which the Reynolds stress term is replaced by the product of the turbulent viscosity (which is a property of the fluid flow) and the mean velocity gradients:

$$
-\rho \bar{u}_{i}^{\prime} \bar{u}_{j}^{\prime}=\mu_{t}\left(\frac{\partial u_{i}}{\partial x_{j}}+\frac{\partial u_{j}}{\partial x_{i}}\right)-\frac{2}{3}\left(\rho k+\mu_{t} \frac{\partial u_{k}}{\partial x_{k}}\right) \delta_{i j}
$$


This approach is associated with the computation of the turbulent viscosity $\mu_{t}$ and the turbulence kinetic energy $k$.

Turbulence modeling is probably the most unresolved problem in classical physics. It is an unfortunate fact that no single turbulence model is universally accepted for all classes of problems. The choice of turbulence model will depend on considerations such as the physics of the flow, the established practice for a specific class of problem, the level of accuracy required, the available computational resources, and the amount of time available for the simulation.

The Boussines hypothesis is used in the SpalartAllmaras model, the $k-\varepsilon$ models, and the $k-\omega$ models. These models of turbulence are implemented in the Ansys Fluent 15. Differences between these models are the method of determining $\mu_{t}$ [14].

Analysis of furnace design, 3-D model, mesh quality, fluid flows and operating modes show that the $k-\varepsilon$ turbulence models group can be used in this study. This type of model is used to solve many engineering problems in CFD-modeling. Ansys Fluent 15 provides three types of $k-\varepsilon$ models: Standard, RNG, and Realizable $k-\varepsilon$ models [15].

The standard $k-\varepsilon$ model presented in ANSYS Fluent was proposed by Launder and Spalding [16]. The $k-\varepsilon$ model is based on the eddy-viscosity (turbulent viscosity) concept and defines $\mu_{t}$ as:

$$
u_{t}=C_{\mu} \rho \frac{k^{2}}{\varepsilon}
$$

The turbulence kinetic energy $k$ and its rate of dissipation $\varepsilon$ are obtained from the following transport equations:

$$
\begin{gathered}
\frac{\partial}{\partial t}(\rho k)+\frac{\partial}{\partial x_{i}}\left(\rho k u_{i}\right)= \\
=\frac{\partial}{\partial x_{j}}\left[\left(\mu+\frac{\mu_{t}}{\sigma_{k}}\right) \frac{\partial k}{\partial x_{j}}\right]+G_{k}+G_{b}-\rho \varepsilon-Y_{M}+S_{k} \\
\frac{\partial}{\partial t}(\rho \varepsilon)+\frac{\partial}{\partial x_{i}}\left(\rho \varepsilon u_{i}\right)=\frac{\partial}{\partial x_{j}}\left[\left(\mu+\frac{\mu_{t}}{\sigma_{\varepsilon}}\right) \frac{\partial \varepsilon}{\partial x_{j}}\right]+ \\
+G_{1 \varepsilon} \frac{\varepsilon}{k}+\left(G_{k}+C_{3 \varepsilon} G_{b}\right)-C_{2 \varepsilon} \rho \frac{\varepsilon^{2}}{k}+S_{\varepsilon}
\end{gathered}
$$

where $G_{k}$ - the generation of turbulence kinetic energy due to the mean velocity gradients; $G_{b}$ - the generation of turbulence kinetic energy due to buoyancy; $Y_{M}$ - the contribution of the fluctuating dilatation in compressible turbulence to the overall dissipation rate; $C_{1 \varepsilon}, C_{2 \varepsilon}, C_{3 \varepsilon}-$ constants; $\sigma_{k}$ and $\sigma_{\varepsilon}$ - the turbulent Prandtl numbers for $k$ and $\varepsilon$, respectively; $S_{k}, S_{\varepsilon}$ - user-defined source terms.
The model constants are: $C_{1 \varepsilon}=1.44 ; C_{2 \varepsilon}=1.92$; $C_{\mu}=0.09 ; \sigma_{k}=1.0 ; \sigma_{\varepsilon}=1.3$

The standard $k-\varepsilon$ model is one of the most widely used turbulence models due to its simplicity and applicability in a modeling range of turbulent flows. A disadvantage of this model is that it does not give satisfactory results for flows involving swirl, rotation, streamline curvature, and splitting of the streamlines. It is mainly due to the eddy viscosity concept used by this model, which assumes the Reynolds stresses to be isotropic. Nevertheless, for CFD modeling this $k-\varepsilon$ model has been selected. This approach has an advantage - it is less computationally expensive compared to other $k-\varepsilon$ turbulent models and for comparing, the simulation results will be used.

The RNG model has a similar form to the standard model [14]. The use of additional restrictions and conditions suggests swirl and low-flow, suitable for complex flows with a transverse velocity gradient, including rapid deformation, reasonable and nonstationary flow vortices.

These features make the RNG model more accurate and reliable for a wider class of flows than the standard model.

$$
\begin{gathered}
\frac{\partial}{\partial t}(\rho k)+\frac{\partial}{\partial x_{i}}\left(\rho k u_{i}\right)=\frac{\partial}{\partial x_{j}}\left[\alpha_{k} \mu_{e f f} \frac{\partial k}{\partial x_{j}}\right]+ \\
+G_{k}+G_{b}-\rho \varepsilon-Y_{M}+S_{k} \\
\frac{\partial}{\partial t}(\rho \varepsilon)+\frac{\partial}{\partial x_{i}}\left(\rho \varepsilon u_{i}\right)=\frac{\partial}{\partial x_{j}}\left[\alpha_{\varepsilon} \mu_{e f f} \frac{\partial \varepsilon}{\partial x_{j}}\right]+ \\
+G_{1 \varepsilon} \frac{\varepsilon}{k}\left(G_{k}+C_{3 \varepsilon} G_{b}\right)-C_{2 \varepsilon} \rho \frac{\varepsilon^{2}}{k}+S_{\varepsilon}
\end{gathered}
$$

The new components compared to Eqs. (13) and (14) are: $\mu_{\text {eff }}$ - effective viscosity, $a_{k}, a_{\varepsilon}$ - the inverse effective Prandtl numbers for $k$ and $\varepsilon$, respectively. The model constants are: $C_{1 \varepsilon}=1.42$ and $C_{2 \varepsilon}=1.68$.

The RNG $k-\varepsilon$ model works well for high Reynolds number flows as well as flows in the transition region and gives improved prediction for flows involving swirl in comparison to the standard $k-\varepsilon$ model.

The "Realizable" $k-\varepsilon$ model contains a new formulation for the turbulent viscosity and a new transport equation for the dissipation rate $\varepsilon$, that is derived from an exact equation for the transport of the mean-square vorticity fluctuation [14]. It eliminates the possibility of unrealistic values of normal stresses from occurring in highly strained flows. For the estimation of turbulent viscosity $C_{\mu}$ it is treated as variable. The variable form of $C_{\mu}$ is a function of the local strain rate and rotation of the 
fluid. An immediate benefit of the "Realizable" $k-\varepsilon$ model is that it provides improved predictions for flows involving rotation, separation, and recirculation.

$$
\begin{gathered}
\frac{\partial}{\partial t}(\rho k)+\frac{\partial}{\partial x_{i}}\left(\rho k u_{i}\right)=\frac{\partial}{\partial x_{j}}\left[\left(\mu+\frac{\mu_{t}}{\sigma_{k}}\right) \frac{\partial k}{\partial x_{j}}\right]+ \\
+G_{k}+G_{b}-\rho \varepsilon-Y_{M}+S_{k} \\
\frac{\partial}{\partial t}(\rho \varepsilon)+\frac{\partial}{\partial x_{j}}\left(\rho \varepsilon u_{j}\right)=\frac{\partial}{\partial x_{j}}\left[\left(\mu+\frac{\mu_{t}}{\sigma_{\varepsilon}}\right) \frac{\partial \varepsilon}{\partial x_{j}}\right]+ \\
+\rho C_{1} S \varepsilon-\rho C_{2} \frac{\varepsilon^{2}}{k+\sqrt{v \varepsilon}}+C_{1 \varepsilon} \frac{\varepsilon}{k} C_{3 \varepsilon} G_{b}+S_{\varepsilon}
\end{gathered}
$$

Table 1

The fuel composition

\begin{tabular}{|c|c|}
\hline Species & Mole fraction \\
\hline $\mathrm{CH}_{4}$ & 0.984 \\
\hline $\mathrm{C}_{2} \mathrm{H}_{6}$ & 0.002 \\
\hline $\mathrm{C}_{3} \mathrm{H}_{8}$ & 0.001 \\
\hline $\mathrm{C}_{4} \mathrm{H}_{10}$ & 0.001 \\
\hline $\mathrm{CO}_{2}$ & 0.002 \\
\hline $\mathrm{N}_{2}$ & 0.01 \\
\hline
\end{tabular}

In these equations, $C_{2}$ and $C_{1 \varepsilon}$ are constants $\left(C_{2}=1.9 ; C_{1 \varepsilon}=1.44\right) ; \sigma_{k}$ and $\sigma_{\varepsilon}-$ the turbulent Prandtl numbers for $k$ and $\varepsilon$, respectively $\left(\sigma_{k}=1 ; \sigma_{\varepsilon}=1.2\right)$. $S_{k}$ and $S_{\varepsilon}$ are user-defined source terms the same as in previous models. But $C_{\mu}$ is not constant and is a function of the mean strain and rotation rates, the angular velocity of the system rotation, and the turbulence fields ( $k$ and $\varepsilon$ ).

For CFD-modeling gas flows and combustion processes in the cyclone furnace, three types of turbulence models were used with combustion models. Solution of the differential equations by finite volumes method was performed. The system of differential equations was supplemented by relevant boundary conditions. The boundary condition is the setting for the inlet, wall and outlet. Operation modes of the furnace are: inlet air $20 \mathrm{~m} / \mathrm{s}$; inlet gas $7 \mathrm{~m} / \mathrm{s}$.

To set up the calculation module, the following assumptions were used:

1. The working volume of the furnace is a mixture of gases (oxygen, nitrogen, fuel, waste products).

2. The heat exchange between the environment and the wall is missing (the walls are "adiabatic").

3. The thermal radiation from the wall in the volume of gas is simulated by the model of discrete ordinate at a constant temperature of $1000 \mathrm{~K}$.

For the Non-Premixed combustion model single mixture fraction probability function (PDF) was used (Fig. 2 ). The fuel composition in mole fractions of the species $\mathrm{CH}_{4}, \mathrm{C}_{2} \mathrm{H}_{6}, \mathrm{C}_{3} \mathrm{H}_{8}, \mathrm{C}_{4} \mathrm{H}_{10}$, and $\mathrm{CO}_{2}$ is presented in Table 1 . For all inlet flows temperature was set as $300 \mathrm{~K}$. $\mathrm{N}_{2}-79$.

The oxidizer (air) consists of (vol \%): $\mathrm{O}_{2}-21$ and

SIMPLE-based approach was used for pressurevelocity coupling scheme. The solution was simulated until convergence was achieved. Approximately 1500 iterations were performed for the case based on the EddyDissipation combustion model and 4500 iterations for the case based on the Non-Premixed combustion model.

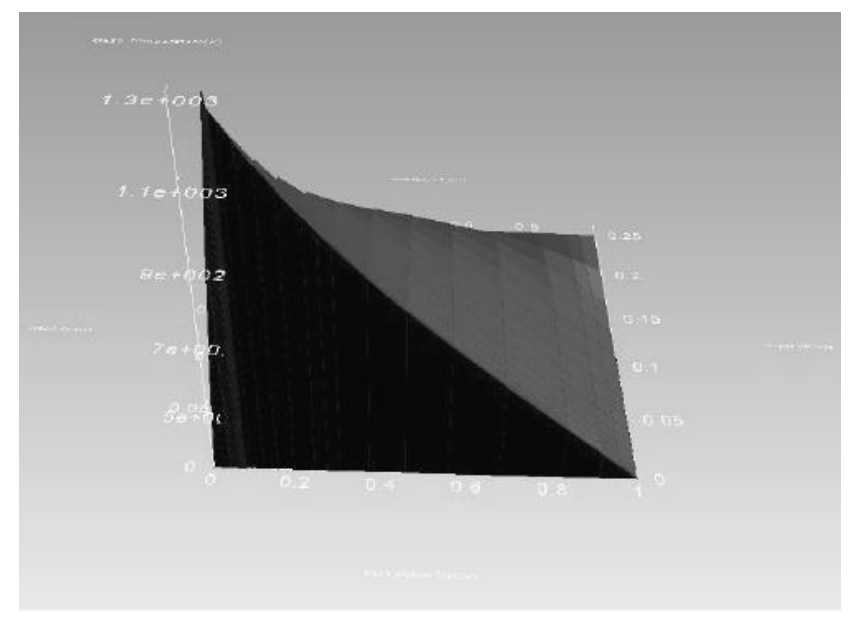

Fig. 2. PDF table for mean temperature, mean mixture fraction and scaled variance

\section{Results and Discussion}

The simulation results from the application of the mathematical models described in the section 2.2 are presented in this section. The results are mainly given in terms of trajectory flows, velocity contours, temperature, and species concentration profiles.

The gas flow distribution and velocity within the cyclone furnace are shown in Figs. 3 and 4 for the both cases based on the "Realizable" $k-\varepsilon$ turbulence models. Case (a) is for Eddy-Dissipation combustion model and case (b) is for the Non-Premixed combustion model. For other types of turbulence models, character of change trajectory flows and velocity distribution are similar.

A large recirculation zone is predicted by all the turbulence models in the conical part of the furnace. The recirculation zone starts from the burner zone and expands to conical section 2 of the furnace and to the central tube. This recirculation zone is formed due to the inlet fuel gas in the furnace through the burner blades where air creates a swirling of the flow. In cylindrical working zone recirculation is low and gases flow to the exit around the central pipe. 


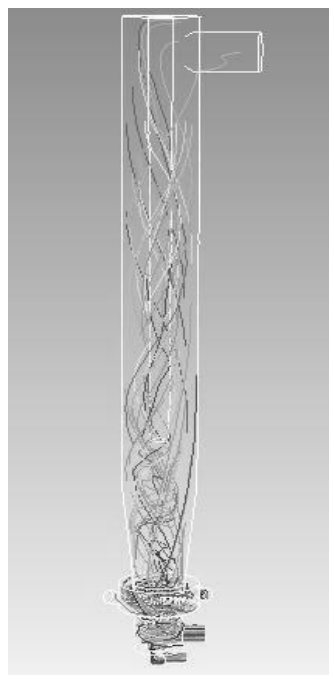

a)

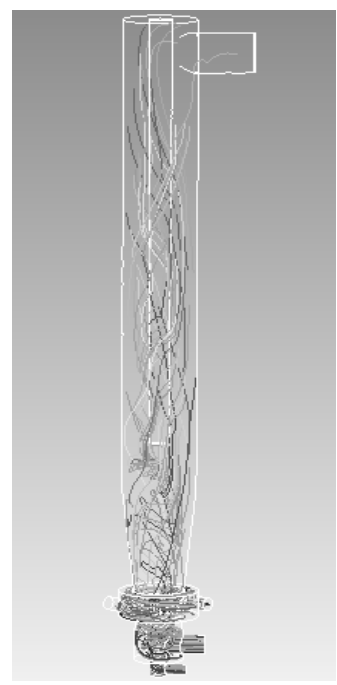

b)

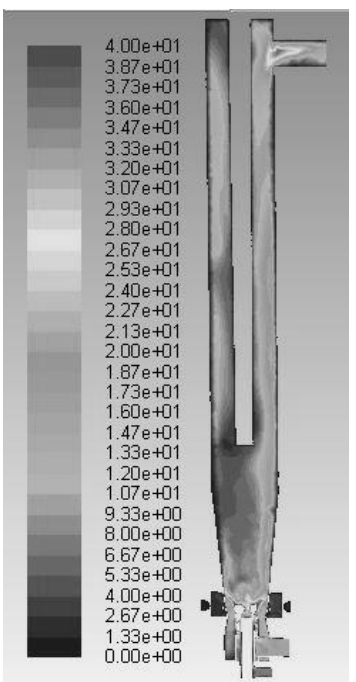

a)

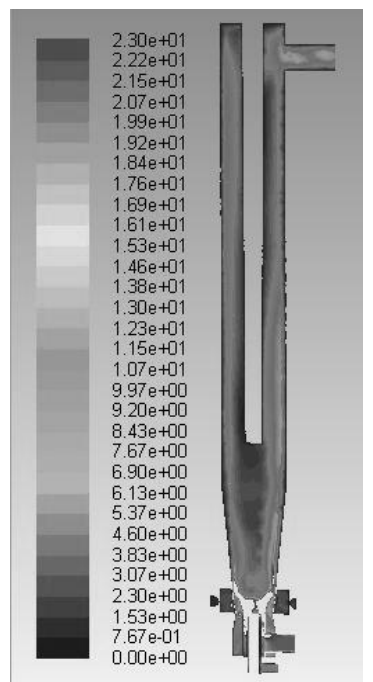

b)
Fig. 3. The trajectory flow distribution in the furnace: EddyDissipation combustion model (a) and Non-Premixed combustion model (b)

As it can be seen in Fig. 4, the velocity contours are dissimilar. Near the walls there are areas of high velocity. Calculated maximum flow velocity near the walls in some areas of the furnace is about $15-18 \mathrm{~m} / \mathrm{s}$. At the exit of the furnace as averaging the square of the velocity is of about $37 \mathrm{~m} / \mathrm{s}$ for case (a) and of about $19 \mathrm{~m} / \mathrm{s}$ for case (b). This is because the gas flow moves spirally. This fact needs attention and is associated with the burner geometry. Probably the burner design must be optimized.

The gas temperature distribution in a vertical cross section through the furnace is shown in Figs. 5 and 6 for the both combustion models, respectively. The high-speed hot combustion gases from the burner zone in conical furnace section flow up to the cylindrical working zone.

This causes higher temperatures in the upper part of conical furnace section that are greater than those predicted for the proposed configuration and operation mode. The uneven mixing also leads to a highertemperature bias towards the right side as the gas leaves the conical section.

A more extended higher-temperature zone is predicted with the Eddy-Dissipation combustion model. For all the cases of turbulent models with the EddyDissipation combustion model the lower temperatures in a small region close to the burners and higher temperatures further away from the burner are observed.

In order to quantify those differences, vertical temperature profiles in the same vertical cross section are shown in Fig. 6 for the Non-Premixed combustion model.

evolution with the Eddy-Dissipation combustion model and the temperature difference between the two models is decreased with height. The maximum tempe-
Fig. 4. The velocity contours in a vertical cross section of the furnace: Eddy-Dissipation combustion model (a) and NonPremixed combustion model (b)

rature predicted with the Eddy-Dissipation combustion model is about $2400 \mathrm{~K}$ whereas the maximum temperature predicted with the Non-Premixed combustion model is about $2100 \mathrm{~K}$. The temperature differences of up to $900 \mathrm{~K}$ are predicted in the region between the conical and cylindrical furnace sections.

In the center of the furnace, where the outlet particles of the central tube are located, a clear local minimum in the flue gas temperature is observed. It is good for the lime calcinations process when particles fall into the low temperature zone and are heated.

It is very important to notice the temperature profile in working zone with the furnace height. The flue gas temperature distribution in the work zone is very important because it is an important factor determining the lime calcinations processes. Due to the high residence time of the flue gas in the working zone and the flow pattern in the furnace shown in Figs. 3 and 4, the temperature contour in a vertical cross section through the cylindrical furnace section predicted with the two combustion models remains approximately constant for each model, respectively (see Figs. 5 and 6). On the contrary, the temperature contour in the conical furnace section outside of the working zone predicted with the two combustion models is very different. This is because the effect of the recirculation has a strong influence on the temperature values in the conical furnace section, where the burner outlet is located. From Figs. 5 and 6 it can be observed that the temperatures in the conical section are very high, since turbulent combustion is dominated at this region and the reactions occur where mixing is high. 


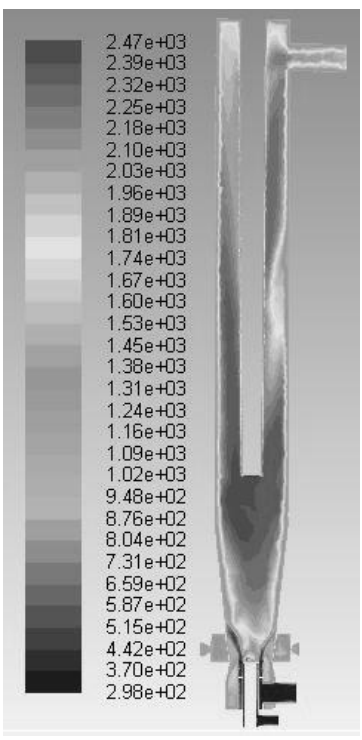

a)

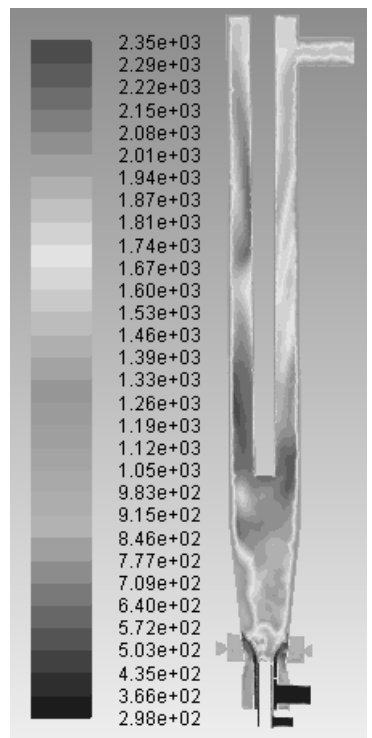

b)

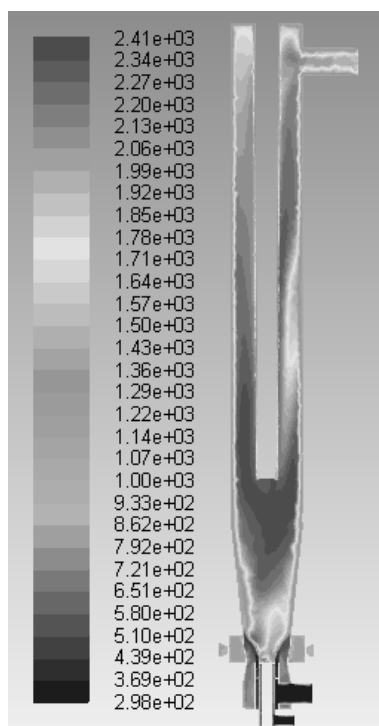

c)

Fig. 5. Temperature profile in a vertical cross section through the furnace based on Eddy-Dissipation combustion model: for $k-\varepsilon$ turbulence model (a); for $k-\varepsilon$ RNG turbulence model (b) and for "Realizable" $k-\varepsilon$ turbulence model (c)

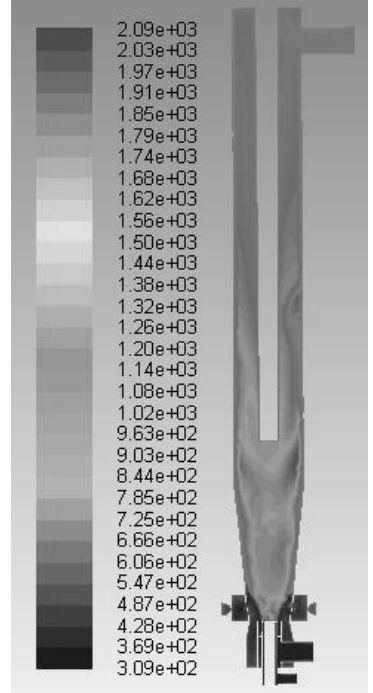

a)

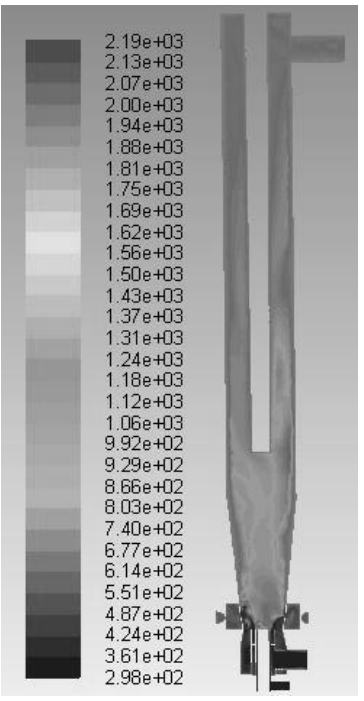

b)

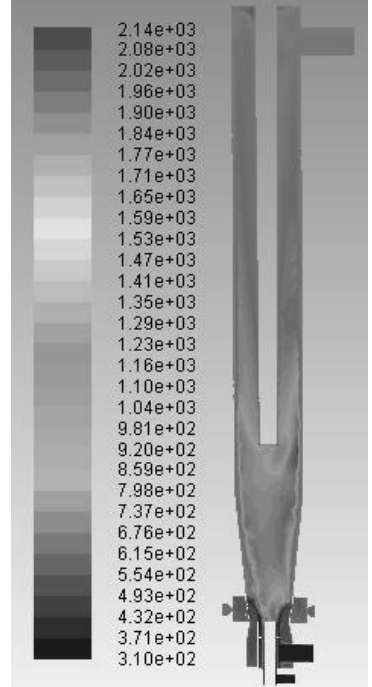

c)

Fig. 6. Temperature profile in a vertical cross section through the furnace based on Non-Premixed combustion model: for $k-\varepsilon$ turbulence model (a); for $k-\varepsilon$ RNG turbulence model (b) and for "Realizable" $k-\varepsilon$ turbulence model (c)

It is shown that the temperature evolution with the Non-Premixed combustion model lags the temperature

Theoretical excess ratio by volume according to a mathematical model is $1: 11.5$. Based on the actual data for this type of burner air excess ratio by volume is in the range of $1: 11.5$ to $1: 12.6$. Under working conditions, the flame length and uniformity of heating are regulated by changing the excess ratio.
The temperature differences predicted with the two combustion models suggest different fuel combustion rates. The concentration profiles of the fuel component $\left(\mathrm{CH}_{4}\right)$ in the same cross section where the temperature profiles have been presented are shown in Figs. 7 and 8 . The results are presented in the same manner as previous results: Fig. 7 is for Eddy-Dissipation combustion model and Fig. 8 is for the Non-Premixed combustion model. 
It is readily noticed that combustion progress for methane is slower in the case of the Eddy-Dissipation combustion model, leading to larger flames when this model is used. Similar results are obtained for the concentration profiles of the major combustion products, namely $\mathrm{CO}_{2}$ and $\mathrm{H}_{2} \mathrm{O}$. The concentration of $\mathrm{CO}_{2}$ and its distribution in the furnace will be considered during the calcination reaction simulation in the future study.

The distributions of $\mathrm{CO}$ concentrations deserve special attention. They are calculated based on NonPremixed combustion model and are shown in Fig. 9.

The process of carbon monoxide combustion is almost complete at the end of conical furnace section indicating that the correct air excess ratio and the correct height of this section were designed.

The experimental measurement of temperature in the furnace was carried out by five sensors located at the apparatus shown in Fig. 10a.
The temperature measurement at the furnace conical section above the burner was not possible and therefore the comparison of the temperature distribution in the furnace with the practical data received on the basis of these 5 measurement points are shown in Fig. 10b.

The distribution of temperatures averaged over the cross section shown in Fig. 10b and calculated on a model Non-Premixed (case 2), showed satisfactory agreement with the practical data that confirms the fundamental picture of the temperature distribution in height, depth and width of the furnace.

These graphs show that the calculation results based on the Non-Premixed combustion model are the closest to the experimental data with "Realizable" $k-\varepsilon$ turbulence model. The maximum relative error is about $14 \%$ for point 1 . For other points, the maximum relative error varies in the range from 6 to $10 \%$.

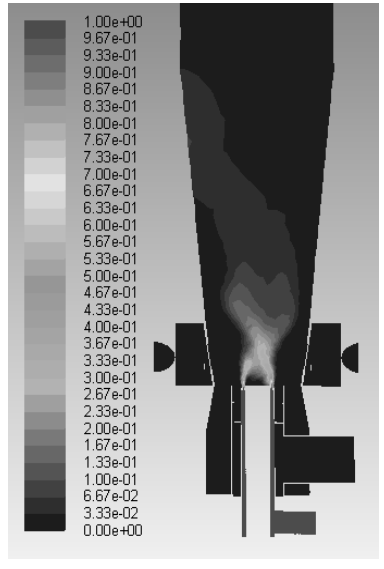

a)

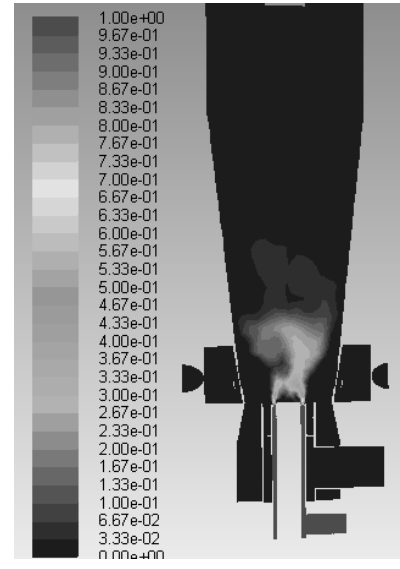

b)

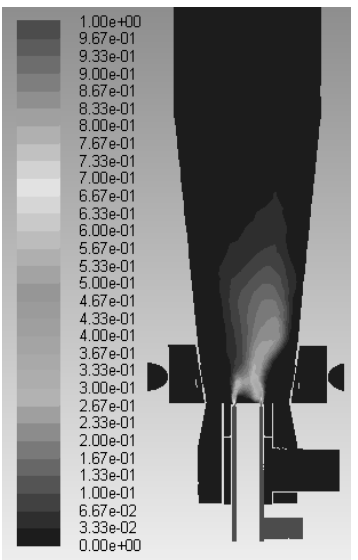

c)

Fig.7. Contours of $\mathrm{CH}_{4}$ mass fractions in a vertical cross section through the furnace based on Eddy-Dissipation combustion model: for $k-\varepsilon$ turbulence model (a); for $k-\varepsilon$ RNG turbulence model (b)and for "Realizable" $k$ - $\varepsilon$ turbulence model (c)

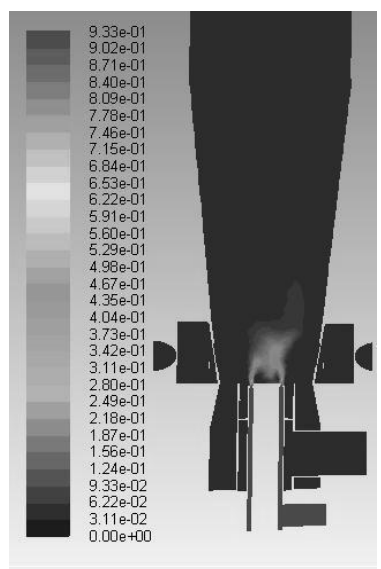

a)

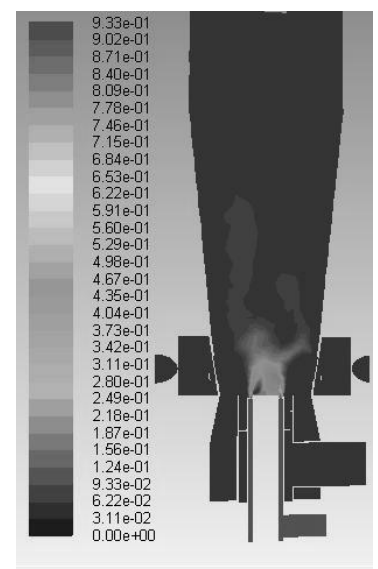

b)

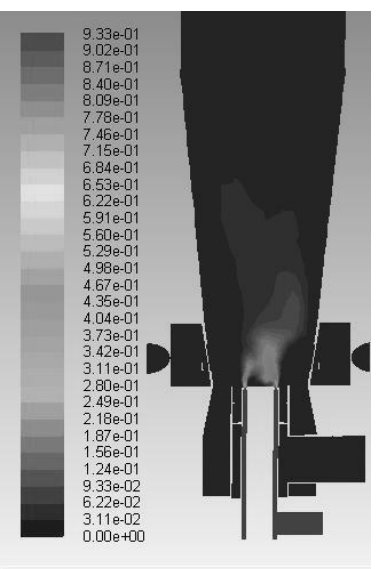

c)

Fig. 8. Contours of $\mathrm{CH}_{4}$ mass fractions in a vertical cross section through the furnace based on Non-Premixed combustion model: for $k-\varepsilon$ turbulence model (a); for $k-\varepsilon$ RNG turbulence model (b) and for "Realizable" $k-\varepsilon$ turbulence model (c) 


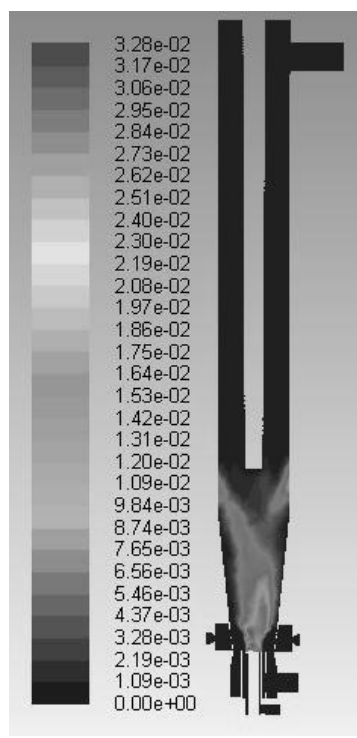

a)

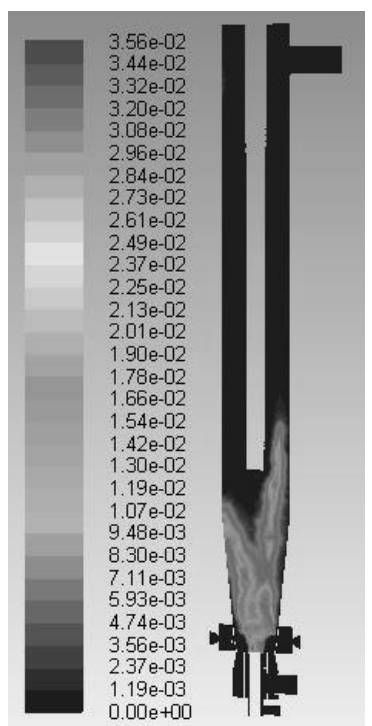

b)

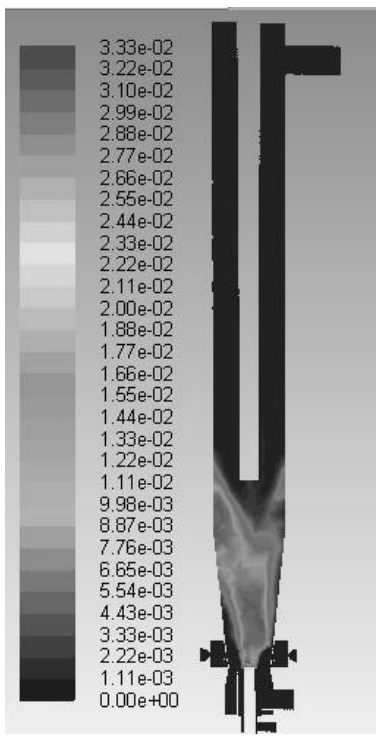

c)

Fig. 9. Contours of CO mass fractions in a vertical cross section through the furnace based on Non-Premixed combustion model: for $k-\varepsilon$ turbulence model (a); for $k-\varepsilon$ RNG turbulence model (b) and for "Realizable" $k$ - $\varepsilon$ turbulence model (c)

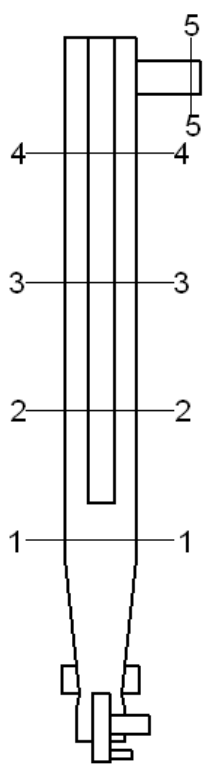

a)

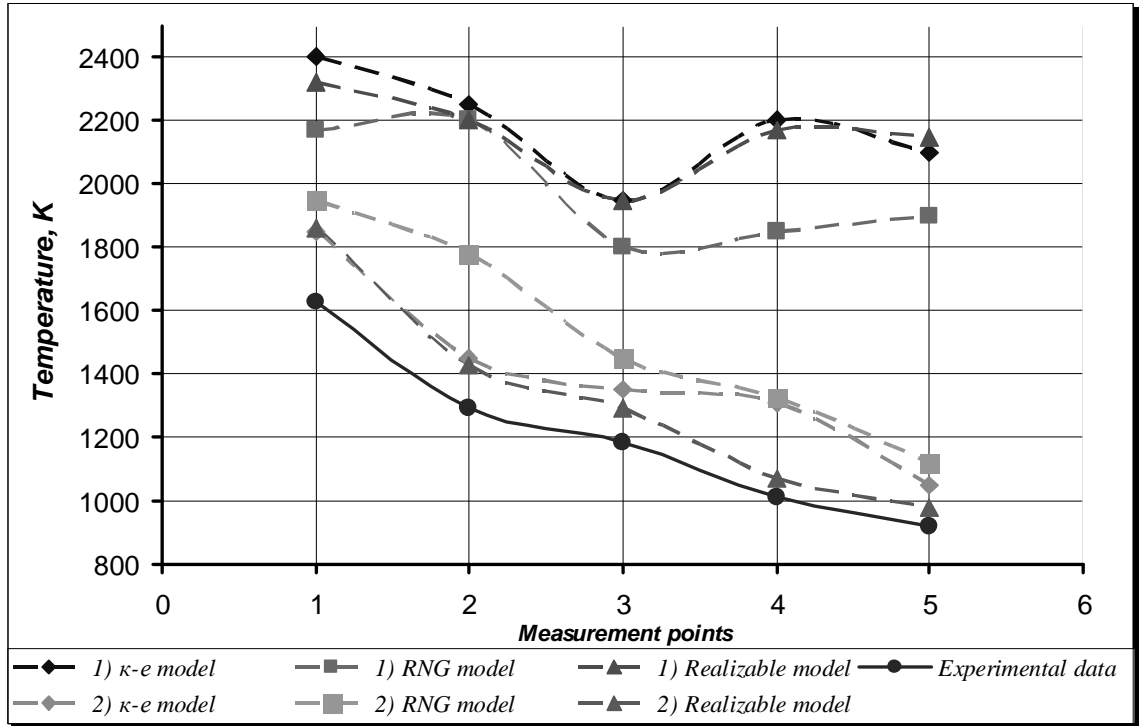

b)

Fig. 10. Experimental measurement of temperature: points of the temperature measure in the furnace (a) and experimental data of the temperature measurement (b)

\section{Conclusions}

In this study, a comprehensive comparison of turbulence models and combustion models for cyclonecalciner furnace was conducted. 3-D field of temperatures in the reaction zone and in the whole system volume, concentration species distribution, and the length of the torch were obtained.

The simulation results were analyzed and validated with the experimental data. The experimental data are in good agreement with the field tests results of the device for the Non-Premixed combustion model with "Reali- 
zable" $k-\varepsilon$ turbulence model. In these points, the error in the calculation of temperature is not more than $10 \%$ in all the calculation options.

The developed computer model provides very important results for better understanding of the complex processes occurring within the furnace and can be a baseline for future modeling of pollutant emissions and limestone calcination processes. The simulation results of calcination reaction based on this model will be presented in the following studies.

\section{References}

[1] Havryliv R., Maystruk V. and Biliak V.: EEJET, 2015, 75, 14.

[2] Artyukhov A. and Sklabinsriy V.: Chem. Chem. Technol., 2015, 9, 175.

[3] Sklabinsriy V., Liaposhchenko O., Logvyn A. and Al-Rammahi M.: Chem. Chem. Technol., 2014, 8, 479.

[4] Magnussen B. and Hjertager B.: $16^{\text {th }}$ Symp. on Combustion. The Combustion Institute, USA, Pittsburgh 1976, 719.

[5] Peters N.: Turbulent Combustion. Cambridge Monographs on Mechanics. Cambridge University Press, Cambridge 2014.

[6] Birkhoff G.: Hydrodynamics: A study in Logic, Fact, and Similitude, $2^{\text {nd }}$ edn. Princeton University Press, Princeton 1960.

[7] Batchelor G.: An Introduction to Fluid Dynamics. Cambridge University Press, Cambridge 1967.

[8] Salvi R. (Ed.): Navier-Stokes Equations. Theory and Numerical Methods. Marcel Dekker, Inc., New York 2002.

[9] Spalart P. and Allmaras S.: Conference Reno, USA, Nevada 1999, 92.

[10] Wilcox D.: Turbulence Modeling for CFD, $1^{\text {st }}$ edn. DCW Industries, Inc., La Canada CA 1993.
[11] Furbo E.: MA thesis. Uppsala University, 2010.

[12] Pope S.: Turbulent Flows. Cambridge University Press, Cambridge 2000.

[13] Schmitt F.: Comptes Rendus Mecanique, Elsevier Masson, 2007, 335, 617.

[14] Orszag S., Yakhot V., Flannery W. et al.: Int. Conf. on NearWall Turbulent Flows, USA, Tempe 1993.

[15] Menter F.: AIAA J., 1994, 32, 1299.

[16] Launder B. and Spalding D.: Lectures in Mathematical Models of Turbulence. Academic Press, London 1972.

Received: April 27, 2016 / Revised: M ay 27, 2016 /

Accepted: September 12, 2016

\section{РОЗРОБЛЕННЯ МОДЕЛІ ГОРІННЯ В ПРОМИСЛОВІЙ ЦИКЛОННІЙ ПЕЧІ-ДЕКАРБОНІЗАТОРІ МЕТОДАМИ ЧИСЛОВОГО МОДЕЛЮВАННЯ}

Анотація. Розроблено тривимірну комп'ютерну модель для дослідження процесу горіння в промисловій циклонній печі-декарбонізаторі. Моделювання руху потоків виконано на основі RANS-niдходу з використанням різних моделей турбулентності. Представлені результати дають можливість спрогнозувати розподіл температури в печі, визначити кониентрачії компонентів в газовій фазі та добре узгоджуються з експериментальними даними. Дані отримані на основі комп'ютерного моделювання будуть використані в наступних теоретичних та експериментальних дослідженнях для оптимізаиії конструкції апарату.

Ключові слова: CFD-моделювання, модель горіння, моделі турбулентності, циклонна піч-декарбонізатор. 